University of Nebraska - Lincoln

DigitalCommons@University of Nebraska - Lincoln

Faculty Publications: Department of Entomology

4-2006

\title{
CREATING \& EVALUATING Artificial Domiciles for Bumble Bees
}

Douglas A. Golick

University of Nebraska-Lincoln, dgolick2@unl.edu

Marion D. Ellis

University of Nebraska-Lincoln, mellis3@unl.edu

Brady Beecham

University of Nebraska-Lincoln

Follow this and additional works at: https://digitalcommons.unl.edu/entomologyfacpub

Part of the Entomology Commons

Golick, Douglas A.; Ellis, Marion D.; and Beecham, Brady, "CREATING \& EVALUATING Artificial Domiciles for Bumble Bees" (2006). Faculty Publications: Department of Entomology. 182.

https://digitalcommons.unl.edu/entomologyfacpub/182

This Article is brought to you for free and open access by the Entomology, Department of at DigitalCommons@University of Nebraska - Lincoln. It has been accepted for inclusion in Faculty Publications: Department of Entomology by an authorized administrator of DigitalCommons@University of Nebraska - Lincoln. 
Published as "CREATING \& EVALUATING Artificial Domiciles for Bumble Bees," Douglas A. Golick, Marion D. Ellis, \& Brady Beecham. The American Biology Teacher April 2006 : Vol. 68, Issue 4, pg(s) e29-e34. Copyright (C) 2006 by The National Association of Biology Teachers. Published by the University of California Press.

Copying and permissions notice: Authorization to copy this content beyond fair use (as specified in Sections 107 and 108 of the U. S. Copyright Law) for internal or personal use, or the internal or personal use of specific clients, is granted by the Regents of the University of California on behalf of the Sponsoring Society for libraries and other users, provided that they are registered with and pay the specified fee via Rightslink ${ }^{\circledast}$ on Caliber (http://caliber.ucpress.net/) or directly with the Copyright Clearance Center, http://www.copyright.com." 


\title{
ONLINE HOW-TO-DO-IT
}

\section{CREAIING \& EVALUAIING Artificial Domiciles for Bumble Bees}

\author{
Douglas A. Golick Marion D. Ellis Brady Beecham
}

\section{hy Study Bumble Bees?}

Bumble bees are valuable pollinators of native and cultivated flora. Wild populations can be found in most temperate zones, and they can be purchased from businesses that supply greenhouses with bumble bees for pollination. Many aspects of bumble bee pollination have been studied extensively, but the biology of most species has not been thoroughly recorded.

In recent years, biologists have documented declines in both managed and wild bee populations (Buchman \& Nabhan, 1996). Factors contributing to the decline include introduced parasites, agrochemicals, urban expansion, and monocultural farming practices. Consequently, a number of programs have begun to conserve and encourage pollinating insects (IBRA, 1996).

Douglas A. Golick is Web Coordinator in the Department of Entomology, University of Nebraska-Lincoln, Lincoln, NE 685830816; email: dgolick@unlserve.unl.edu. MARION D. ELLIS is Associate Professor in the Department of Entomology, University of Nebraska-Lincoln, Lincoln, NE 68583-0816; email: mellis3@unlserve.unl.edu. BRADY BEECHAM is Public Health Researcher for the Achuta Menon Centre for Health Sciences in India.

\section{Why Study Artificial Domiciles?}

Most biologists agree that the availability of suitable nesting sites is a limiting factor for bumble bee populations (Free, 1959). Bumble bees always select areas with preexisting insulation for nesting. Fur-lined abandoned rodent dens are especially attractive, but occasionally, abandoned man-made materials are inhabited. It is not rare to find multiple dead queens in a nest indicating that they have fought for ownership.

Despite our knowledge of bumble bee nest site selection, most efforts to attract bumble bees to artificial domiciles have been met with limited success (Fye \& Medler, 1954; Hobbs et al.,1960). Creating and evaluating artificial domiciles provides students an opportunity to investigate a real problem. In conducting their investigation, they will learn about the biology and life cycle of bumble bees, their vital role as pollinators, and the interdependence of the bees and plants they visit. They will also have an opportunity to contribute to solving a problem that could greatly enhance bumble bee conservation efforts. Developing a highly-attractive artificial domicile would help to increase local bumble bee populations and benefit the plants they pollinate, including many fruit and vegetable crops. An attractive artificial domicile would also be invaluable to researchers who study bumble bees. 


\section{Avoiding Stings}

Away from their nest, bumble bees sting only if handled. Near their nest, bumble bees respond defensively to vibration and rapid movement. Students need not handle bumble bees or open their domiciles to complete this project. This lesson was used in the Bumble Boosters project (Golick \& Ellis, 2003). Although thousands of students participated in this project, not a single sting was reported. For more information on Bumble Boosters visit http://bumbleboosters.unl.edu.

\section{The Lesson}

In this lesson, students are challenged to develop artificial domiciles and to evaluate their success in attracting bumble bee queens. This lesson teaches students to follow the scientific method. Participants formulate a hypothesis and then design an experiment to test their hypothesis. Students manipulate variables to test their hypotheses including domicile structure materials, insulating materials, and field placement location. Students will create several replications of their design, place them in the field, and periodically monitor them for occupancy. To close the lesson, students draw conclusions as to why their design did or did not work as a guide to other students continuing the investigation.

Artificial domiciles are placed in the field during spring. Occupancy is determined when bumble bees are observed coming and going from domicile entrances. Alternatively nests may be opened in the fall, when bumble bees are no longer active, to check for evidence of occupancy (i.e., nest remnants).

\section{Lesson Audience}

Middle and high school students

\section{Vocabulary}

hypothesis

variable

experimental design

domicile

bumble bee

scientific method

\section{Materials}

Consider how materials will withstand the natural elements. Use household or recycled materials like wood, plastic soda containers, cardboard, wire mesh, and plastic tubing. Some bumble bee species nest underground while other species nest on the surface. A shovel will be needed to bury nests that are placed underground. Flags made of wire with fluorescent tape are helpful in relocating nests. Students should maintain a journal that includes their design and observations.

\section{Educational Goals}

1. Elevate student awareness of the importance of pollinating insects and factors that affect their abundance.

2. Involve students in a "real" scientific investigation that will require critical thinking to design an experiment, test for variables, and evaluate data.

3. Guide students in applying the scientific method in a context with the possibility of negative results.

4. Increase student skills in presenting and reporting the results of a scientific investigation.

5. Guide students in examining previous results to design new experiments.

\section{Teacher Background}

Two methods of establishing bumble bee colonies have been investigated.

In the first method, a queen is collected soon after she emerges from hibernation and confined in a nest box. In the mid-1980s, a Dutch company developed techniques for rearing bumble bees in captivity. Some of the information on rearing bumble bees in captivity has been published, but much remains proprietary. Colonies reared in captivity sell for approximately $\$ 200$ each and are used extensively in greenhouses to pollinate cucumbers, tomatoes, and other crops. The second method of establishing colonies is to attract queens to artificial domiciles placed in natural settings. This is a less labor-intensive method and is better suited for small-scale pollination and observation. Declining pollinator populations have increased interest in developing a reliable method of attracting bumble bees to artificial domiciles. To date, researchers have not found a reliable way to attract nest seeking bumble bee queens.

\section{Lesson Steps}

\section{Step \#1. Nests in Nature}

Before designing an artificial domicile, it is important to know why queens select certain nest sites and what these natural nests have in common.

One of the most important factors in the success of bumble bees is nest selection. In early spring, bumble bee queens emerge from hibernation and begin looking for a suitable site to establish a nest. This is the only time that bumble bee queens will initiate nests. They may spend several weeks searching for a suitable nesting site (Alford, 1975). Bumble bees do not create their own nest cavity or forage for insulating materials. In both surface and underground nesting species, suitable nest sites must be dry, protected from predators, and have pre-existing insulating material. Bumble bees often select an abandoned rodent den as a place to initiate a nest. Locating natural nests can provide valuable insight about designing artificial domiciles. However, looking for nests is time consuming and 
may not be a productive class activity. If students observe natural nests, they should be encouraged to keep a journal of their observations to compare with classmates' observations.

Below are helpful hints and resources for starting students on the investigation process:

- Review books on bumble bee biology. Bumblebees (1975) by D.B. Alford and The Humble Bee (1989) by S.W. Sladen both provide a good overview of bumble bee biology.

- A field trip to sites where bumble bees are readily observed is a good way to stimulate students to think about ideas for their artificial domiciles. Areas that would be attractive to mice for nesting such as field edges are good places to look. Bumble bee nests have also been found under dog houses, in woodpiles, in compost heaps, in hay bales, and in underground nests made by ground squirrels.

- The Bumble Boosters Web site (http://bumbleboosters.unl.edu) has information about bumble bee biology, nest architecture, and nest selection.

\section{Step \#2. Artificial Domiciles}

Researchers have tried to mimic natural nests by manipulating different variables. Below are a few of the variables that have been considered in previous research. Students are encouraged to include some of these variables while designing their artificial domiciles as well as other variables they identify from their reading and field trips.

\section{Variables}

\section{Location of Nests}

- Some species of bumble bees nest on the surface and others nest underground. To attract both types, consider designing some domiciles for placement on the ground and others for underground. In some underground designs you may need an entrance tunnel leading to the ground surface.

- Nests must be dry. Queens will likely abandon a nest that becomes wet.

- Tunnels leading up from underground nests should not be slick because bees have difficulty walking on smooth surfaces. Entrance tunnels should also be wide enough for two bees to pass each other.

- Naturally occurring nests are usually in an area that provides foraging plants throughout the summer.

- Marking domiciles may help attract searching queens and allow them to more easily orient themselves to the nest. Researchers have painted nests, marked them with flags, and placed objects such as logs over them in an attempt to aid the queen in finding the nest.

\section{Domicile Design}

- Researchers have made artificial domiciles out of terra cotta, tin plate, wood, cheese cloth, wire mesh, plastic, concrete, soil, and other materials.

- The size of the artificial domicile cavity may be an important factor. Keep in mind that as a colony develops, it may need more room to accommodate growth.

- Some researchers have put gravel or sand in the base of the nest to encourage drainage.

\section{Time of Year}

Queen emergence varies depending on the geographical location and the species occurring in the area. Throughout the U.S., bumble bee queens typically emerge with the first spring blooming flowers. In eastern Nebraska this happens in mid-March. Queen emergence is also staggered by species with some emerging as late as early summer. Domiciles should be placed on site before queens begin their spring emergence to provide all species in your area an opportunity to occupy them.

\section{Scent of the Nest}

Bumble bees are often found in abandoned rodent dens. It may be possible that the bees are attracted to a chemical message left by a previous rodent inhabitant or to the scent of another queen.

\section{Protection from Predators}

Bumble bee nests are sometimes attacked by ants, mice, and skunks. Domiciles can be protected from rodents by making their entrances large enough for bees to enter and exit freely, but too small for rodents to enter. About $1.27 \mathrm{~cm}$ to $1.90 \mathrm{~cm}$ diameter is recommended. Domiciles can also be protected from ants and wood roaches by placing the domiciles above ground on a $30 \mathrm{~cm}$ wooden post wrapped with fly paper.

\section{Nesting Materials}

Bumble bees need soft insulating material to cover their nest. Instead of gathering it on her own, a queen chooses a site with pre-existing insulating materials like a mouse or bird's nest. Some materials that researchers have used in artificial domiciles include: soft grass clippings, cotton batting, shredded paper, and compost material. Avoid materials such as wool that may entangle the bees' legs.

\section{Observing Domiciles}

Opening or rearranging a domicile early in the season may cause an established queen to abandon the nest. A good design will allow observers to check the domicile with minimal disturbance. After the first brood has emerged, bumble bees will defend the nest rather than abandon it. 


\section{Step \#3. Designing and Building Artificial Domiciles}

Students are encouraged to consider the observations reported by others and their own observations of natural nests when designing their artificial domiciles. Below are recommended steps for designing and building artificial domiciles.

- Decide whether the domicile will be placed above or below ground.

- Select artificial domicile designs. Students will generate many different designs. Focusing attention on a few designs helps to narrow down the variables involved in solving the problem. Taking a vote or using small groups are ways to choose a few designs for replication.

- Gather construction materials for use in the artificial domiciles. Using recycled materials such as plastic bottles, wood scraps, and used pottery encourages a conservation ethic. Bumble bees may be repelled by odors associated with new materials.

- Make and test artificial domiciles. Placing a copy of each model out in the field for a few days will reveal design flaws. If the artificial domicile becomes wet or damaged, design modifications should be made.

- Design replication. Artificial domiciles should be replicated and placed in a variety of locations. Both macro and micro geographical features should be taken into account.

\section{Step \#4. Placing Domiciles in the Field}

Bumble bees can be found in both urban and rural environments. Most successful artificial domiciles will be

\section{Figure 1.}

\section{Figure 2.}

Students from Clearwater High School constructed these wooden domiciles. Photo: Jeff Meyer

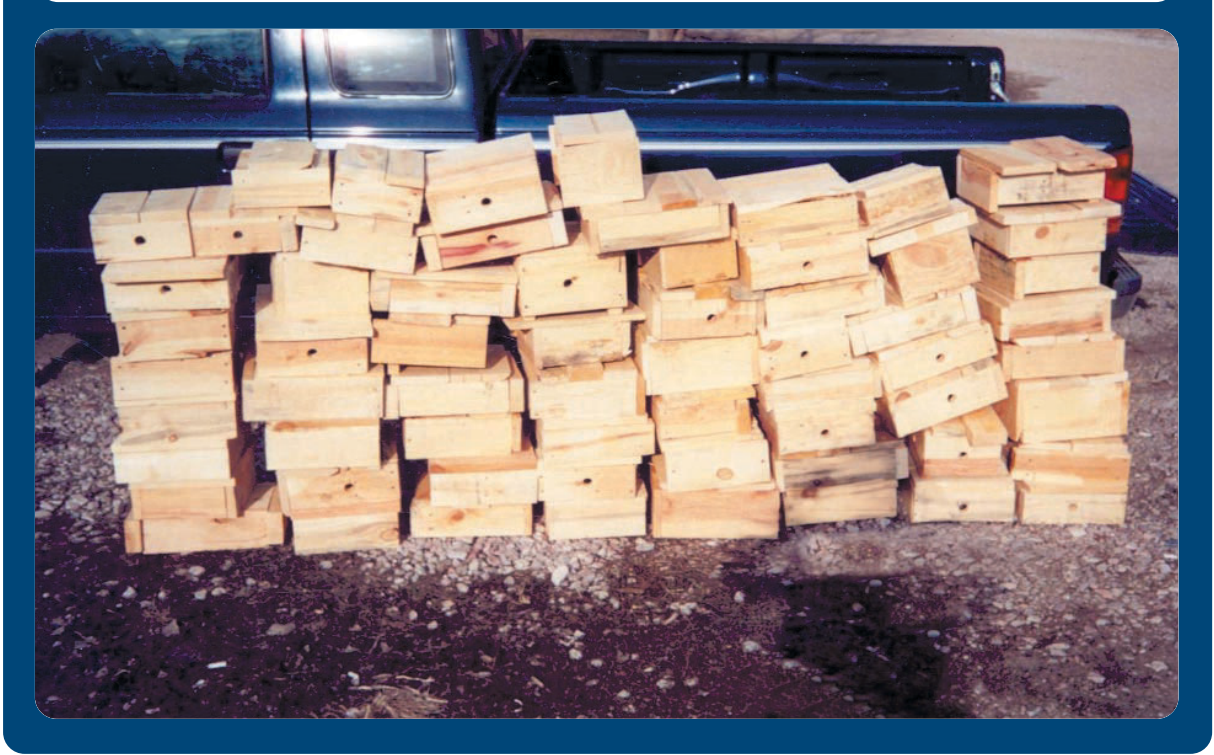

Students placing domiciles in the ground prior to queen emergence. Photo: Marion Ellis

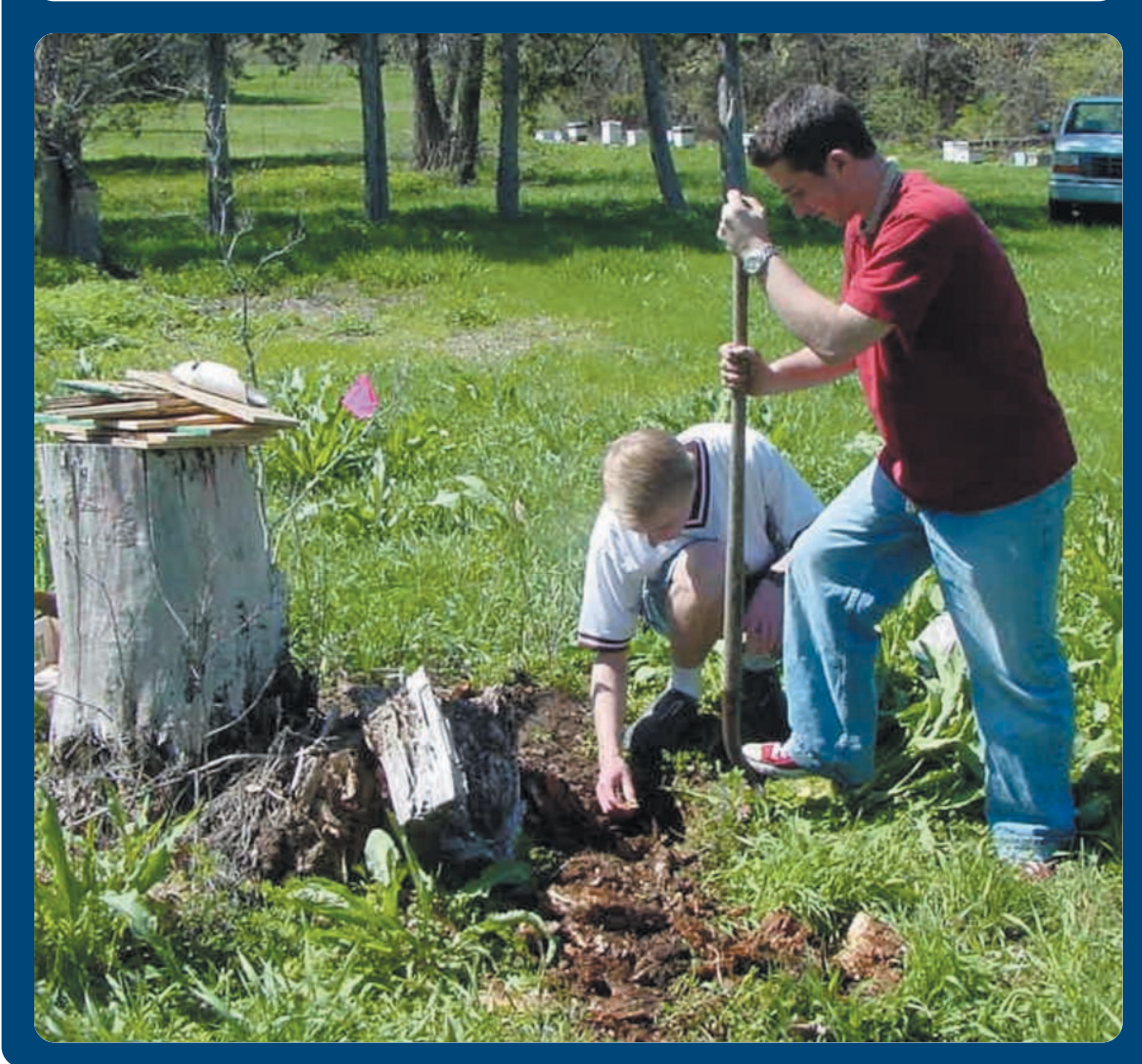

located in areas where bumble bees have been spotted before, usually within a half-mile of spring-blooming plants. Within a test location, consider the placement of 
domiciles in relationship to other site characteristics (i.e., streams, fence rows, trees, and buildings). In each location, it is important to conduct several replications with each artificial domicile design. Drawing a map and placing a flag near each domicile will aid in locating nests later in the season. Global positioning system (GPS) devices are very helpful if available. Taking photographs of artificial domiciles and surroundings during placement is a useful tool for recording data.

\section{Step \#5. Observing Domiciles/Recording Data}

To measure the success of a domicile design in attracting bumble bee queens, occupancy data should be recorded. Each domicile should be checked for occupancy twice: once in the spring and once in the late summer or fall. In the spring, queens are likely to abandon disturbed domiciles. Avoid changing the domicile location or surroundings. The best time to make early observations for domicile acceptance is in June, after most bumble bee species have emerged from hibernation. The second observation may be made in the late summer or fall. To accommodate a typical academic calendar year, domiciles may be checked as early as May for first occupancy and as late as October for continued habitation. It is important to remember occupancy observations made in May do not account for those species that may later occupy a domicile.

During observation and data collection, it is important to remain 3-5 meters away from the entrance of the domicile to avoid disturbing the colony. In the spring and summer, domiciles should be observed 15 minutes for bees coming and going. After 15 minutes of no observed activity, you may check for evidence of occupancy. (By this time it is unlikely that bees are in the nest as they are either out foraging or do not occupy the domicile.) In the final fall observation, bumble bees are likely to have become dormant or have abandoned their nests. Observe domiciles as in the spring and summer observations, and record evidence of bumble bee occupancy such as nest remains (see Figure 3). Also, take careful note of any other organisms that may have occupied the nest such as wax moths, ants, and rodents.

\section{Step \#6. Review Data/Evaluate Domiciles}

Talking about the attributes of both successful and failed designs can help identify the key variables in attracting queens to artificial domiciles. In these discussions, students will examine the variables and develop hypotheses about artificial domiciles. Remind them not to be discouraged if their nests are not occupied. This is a "real" investi- gation, and unlike some teaching exercises, the answer is unknown. Scientific investigation often requires years of trial and error before problems are solved.

\section{Questions for Discussion}

What variables do you think contributed to the success of nests that attracted queens?

What variables do you think contributed to the failure of unsuccessful nests?

Is there any one variable that successful domiciles have in common?

Was the location (macro and micro) of your domiciles an important factor in their success or failure?

How would you improve the design of your artificial domiciles to better attract queens?

\section{Expected Results}

Designing an attractive domicile is a real-world problem. The limited success by previous researchers provides students with an opportunity to contribute to our understanding of nesting domicile preferences. Based on previous studies, highest queen acceptance rates that can be expected of domiciles range from $32 \%$ to $45 \%$ (Frison,1926; Fye \& Meddler, 1954; Hobbs, 1967). In less desirable domicile designs (those that do not keep out rain water, attract invaders, and do not have suitable insulating material), acceptance rates are likely to be much lower. Nest designs that yield poor results may be disappointing to teachers and their students. However as scientists and educators, we believe that experiments that can fail to achieve the desired result should be included in education. They stimulate students to ask why, and to think about how to apply what they learned from failed experiments to conduct more investigations. It should be remembered that most experiments conducted by scientists do not achieve the hoped-for result. The process of re-evaluation and interpretation of results is a vital part of a scientific investigation. Domicile designs that are successful can be used as a standard to which other designs are compared. Alternatively, designs not occupied in one season can be used as controls to compare new domicile designs.

\section{Conclusions}

The lesson is concluded when students present their findings to their classmates. As a class, students should create a short written report outlining their findings, including recommendations about which variables were or were not important in attracting bumble bees to their artificial domiciles. This report is similar to what scientists do in 
presenting experimental results to their peers in manuscripts and at meetings.

\section{Acknowledgments}

The authors would like to thank the teachers and students who participated in Bumble Boosters. Their hard work and constructive feedback were essential in the improvement of the project's lesson plans. The authors would also like to acknowledge the Nebraska Lottery's Educational Innovation Fund for providing financial support for Bumble Boosters.

\section{References}

Alford, D. V. (1975). Bumblebees. London: Ebenezer Baylis \& Son Ltd.

Buchmann, S. L. \& Nabhan, G.P. (1996). The Forgotten Pollinators. Washington, D.C: Island Press.

Bumble Boosters Project Web site: http://bumbleboosters.unl.edu.

Golick, D.A. \& Ellis, M.D. (2003). Bumble boosters: Doing science as a community of learners. American Entomologist, 49(2), 7680.

Free, J. B. \& Butler, C.G. (1959). Bumble Bees. New York, New York: Macmillan.

Frison, T.H. (1926). Experiments in attracting bumble bee queens to artificial domiciles. Journal of Economic Entomology, 19, 14955 .

Fye, R. E. \& Medler, Jr. T. (1954). Field domiciles for bumblebees. Journal of Economic Entomology, 47, 672-676.

Hobbs, G.A., Virostek, J. F. \& Nummi, W.O. (1960). Establishment of Bombus spp (Hymenoptera: Apidae) in artificial domiciles in Southern Alberta. Canadian Entomologist, 92, 868-872.

Hobbs, G.A. (1967). Obtaining and protecting red-clover pollinating species of Bombus (Hymenoptera: Apidae). The Canadian Entomologist, 99: 943-951.

Matheson, A. (Editor) (1996). Bumble Bees for Pleasure and Profit. Cardiff Bay, U.K: International Bee Research Association (IBRA).

Sladen, F. W. L. (1989). The Humble-bee, its Life History and How to Domesticate It. London: Logaston Press. 